\section{Unnecessary Pain, Nutrition, and Vegetarianism 1}

\author{
Jack Weir \\ Hardin-Simmons University
}

Editors' Note: Abridged versions of this paper, the commentary on it by Professor Sapontzis, and Professor Weir's response were delivered at the Eastern Division meeting of the Society for the Study of Ethics and Animals held in Atlanta, Georgia, December, 1989.

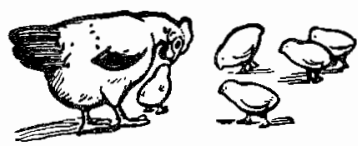

"The meat we eat is no more nourishing than the grain the animals are fed."

-James Rachels, "Vegetarianism and 'The Other Weight Problem'," p. 185.

"...whatever else be true, whether there be gods or only atoms, whether men are significantly superior to non-human animals or no, whether there be life to come or this poor accident be all, this at least cannot be true, that it is proper to be the cause of avoidable ill. There may be other moral principles than this, but this at least is dogma. And if this minimal principle be accepted, there is no other honest course than the immediate rejection of all flesh-foods and most bio-medical research."

-Stephen R. L. Clark, The Moral Status of Animals, p. xiii.

\section{Introduction}

This paper is an analysis of one of the main moral arguments for vegetarianism, the vegetarian argument from unnecessary pain. This argument is derived from

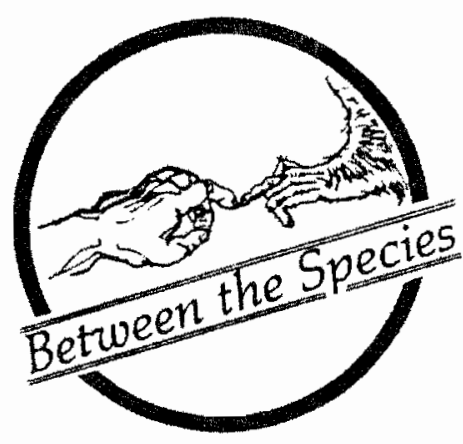

the moral principle that unnecessary pain is wrong, and obviously the soundness of any argument using the principle depends on what is meant by the terms 'unnecessary' and 'pain.' The term 'unnecessary' can refer to either: (a) an end that is itself unnecessary (and, therefore, whatever pain is endured in gaining the end is a fortiori unnecessary); or (b) an unnecessary means to a necessary end (namely, the means is unnecessary because another means is available). My concern in this paper is with the second interpretation, and so I can make only a few brief remarks about the first. ${ }^{2}$ Although the term 'pain' functions in both, its analysis is best undertaken as part of the longer, fuller analysis.

Briefly, regarding unnecessary ends, since in the vegetarian argument the end is adequate human nutrition, the end is not unnecessary if human beings are to survive. In contrast to adequate nutrition, more obviously unnecessary ends are using animals for decoration (taxidermy), symbols of social status (furs and exotic birds), and entertainment (rodeos). These latter ends are nonessential for human survival and suitable substitutes are readily available for achieving the same ends. In contrast, nutrition is significantly necessary: humans cannot be healthy and free of suffering without it, we eventually will die without it, other ends are severely limited when we are unheal thy or suffering, and other ends are impossible when we ane dead. Nutrition is obviously not a final end in itself

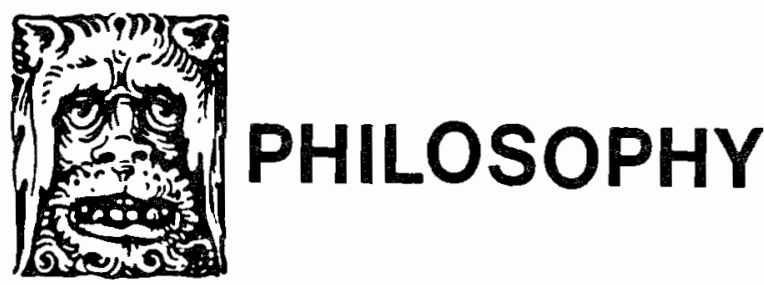


but is a means to some further ends, such as a healthful life or the Good Life. Although the Good Life can be achieved without rodeos and stuffed, mounted animal corpses, it cannot be achieved without adequate food.

According to classical hedonistic utilitarianism, the end to be maximized is pleasure, not human nutrition. If pleasure is the summum bonum and all pleasures are equal, including human and other animal pleasures, then adequate human nutrition as an end should be overridden in all cases where greater pleasure would result from human malnutrition and death, including perhaps the demise of the entire human species. As I argue below, the mere plausibility of this argument is a reductio ad absurdum for hedonistic utilitarianism.

I take it that there can be no serious objection to the necessity as an end of adequate human nutrition, and so this first reading of the term 'unnecessary' will not be pursued further. I turn now to may main concern in this paper.

\section{The Extended Argument}

The second reading of 'unnecessary' requires a "multiple means" calculus in which two or more means are contrasted according to the principle of unnecessary pain. The result is an extended argument involving three steps, as outlined below:

\section{I}

1.10 A vegetarian diet is adequate for human nutrition.

1.20 A meat (omnivorous) diet is adequate for human nutrition.

1.30 Therefore, a meat (omnivorous) diet is unnecessary for human nutrition. (From $1.10,1.20)$

\section{II}

1.40 A vegetarian diet causes no pain to the animals.

1.40 A meat diet causes pain to the animals.

1.60 Therefore, a meat diet causes unnecessary pain. (From 1.30, 1.40, 1.50)

\section{III}

1.70 Causing unnecessary pain is wrong.

1.80 Therefore, a meat diet is wrong. (From $1.60,1.70$ )
This argument has convinced many to be vegetarians, but is it sound? It needs careful analysis for conceptual, logical, and empirical correctness. Based on the more questionable claim in each, I am labeling the three subarguments, respectively, the Empirical Argument from Nutrition, the Empirical Argument from Pain, and the Moral Argument from Unnecessary Pain.

\section{The Empirical Argument from Nutrition ${ }^{3}$}

In the Empirical Argument from Nutrition, the formal structure of the argument is valid. In other words, if the premises $(1.10,1.20)$ were unambiguously twe, then the conclusion that meat-eating is unnecessary (1.30) would follow from the premises. Logically: $p$ is 'necessary' for $q$ if and only if $q$ will not obtain without $p$; and, $p$ is 'unnecessary' for $q$ if $q$ will obtain without $p$, that is, if there is another possible cause for q. In the Empirical Argument from Nutrition, the goal is adequate nutrition, and two means are allegedly possible, a meat diet and a vegetarian diet. The presumed availability of the vegetarian diet makes the meat diet "unnecessary." The logic of this argument is indisputable. However, I argue below that the conclusion does not follow because Premise 1.10 confusingly equivocates what is meant by "vegetarian" and "adequate." Literally as stated, Premise 1.10 is either false or ambiguous, and therefore must be revised.

Vegetarianism is not even initially plausible unless the diet is nutritionally adequate (1.10). Despite the claim's central importance, often it is merely asserted without qualification or support, as by James Rachels when he states, "The meat we eat is no more nourishing than the grain the animals are fed." 4 Most discussions favoring vegetarianism give the claim only cursory treatment, usually by citing as proof the large numbers of vegetarians who are "hale and thriving." "Worldclass athletes, Hindus, Seventh-Day Adventists, and Trappist monks often are listed as evidence of the diet's healthfulness. ${ }^{6}$

Obviously this is an inductive hasty generalization: the empirical fact that some vegetarians are healthy does not prove that all humans-or even most humans - will be healthy on a vegetarian diet. Minimum Daily Requirements (MDRs) vary from person to person and from ethnic group to ethnic group. Just as particular individuals and ethnic groups are susceptible (or immune) to certain diseases (such as sickle cell anemia and skin cancer), particular individuals and ethnic 
groups (especially those from colder climates traditionally dependent on large quantities of meat and dairy products) may require more of the nutrients found in meat due to centuries of high meat consumption and natural selection. Their gastrointestinal tracts may not digest and absorb adequate nutrients from purely nonanimal sources. Moreover, of the "hale and thriving" vegetarians cited as proof, most are not strict vegetarians (vegans) but rather eat eggs (ovovegetarians) or milk products (lactovegetarians) or both (ovolactovegetarians). In addition, many take vitamin and nutrient supplements, and many have suffered illhealth from their diet. For instance, cited by Jane Brody as proof of the healthfulness of vegetarianism, ${ }^{7}$ Bill Walton, star of the Portland Trailblazers, suffered numerous bone fracture problems due to his diet. ${ }^{8}$ Despite the fact that three-fourths of them took supplements, a recent nutritional analysis of ovolactovegetarian Trappist monks found that "a number of the subjects had low intakes of some nutrients, particularly the B-vitamins and calcium, iron, magnesium, and zinc." 9

Listed below are several empirical facts ${ }^{10}$ that limit the scope of Proposition 1.10:

1. Vitamin B-12 is an essential nutrient and naturally occurs only in animal products (meat, eggs, and dairy products). Absent from humans, microorganisms in the intestines of other animals synthesize the vitamin. Deficiency in B-12 causes Pernicious Anemia, gastrointestinal disorders, neurological impairment, and eventually death. Consequently, vegans must supplement their diet with vitamin pills, tempeh or miso (soy) fermented with the Klebsiella bacteria, yeast grown on media rich in B-12, or foods artificially fortified with B-12. For these reasons, many vegetarians are ovolactovegetarians.

2. If the worldwide human population depended solely on eggs and dairy products for balanced nutrition, huge additional quantities would be needed. For example, three whole eggs or three cups of whole milk (or seven cups of skim milk) must be consumed to obtain the MDR of B-12. Without meat in the diet, hens and cows would have to be exploited far beyond current levels. What should be done with the hens and cows when they stop producing? To get the milk, cows must have calves. What happens to the calves, especially the bull-calves? Moreover, unprocessed eggs and milk have significant amounts of saturated fats and cholesterol, which contribute to heart disease, and many people are unable to eat dairy products due to a lactose intolerance. The B-12 in eggs is in the cholesterol-laden yolk, not the protein-rich egg white that can be eaten without danger. An alternative would be to rely on vitamin supplements.

3. Vegetarians are at risk of developing Iron Deficiency Anemia because only 5-10 percent of the iron in vegetables is absorbed during digestion. The large amounts of fiber in vegetarian diets bind up the iron preventing absorption. In contrast, via a different biochemical process, $10-30$ percent of the iron in meat is absorbed. Although the iron is readily available in vegetables, a haphazard diet will be deficient. As with B-12, vitamin supplements may be taken; but, unlike B-12, iron can be toxic. Iron supplements can also cause gastrointestinal disturbances.

4. Increased amounts of iron are required by menstruating women, pregnant women, adolescent boys and girls, and old people (usually due to small amounts of internal bleeding) - that is, all age groups except adult males. Vegetarians in these groups are especially at risk of developing Iron Deficiency Anemia and therefore are advised by authorities to monitor their diets closely or else take supplements.

5. Pregnant women and nursing women who are vegetarians are especially susceptible to deficiencies in all the B vitamins. They should consume eggs, dairy products, or supplements.

6. Infants and preschool children need animal protein, at least eggs or dairy products. Even with an ovolactovegetarian diet, they may also need supplements. Vegan infants and children are usually malnourished, underweight, and neurologically underdeveloped. Nevertheless. with careful attention to their children's diets, 
some vegans have been able to raise healthy preschool children.

7. Protein needs vary depending upon stress, disease, injury, loss of sleep, activity, and other factors. Although adequate protein normally can be obtained from complementary vegetable sources, the protein in cereals, legumes, and nuts is less digestible and less balanced than that in meat, eggs, and milk.

8. Vegan diets are also especially susceptible to deficiencies in calcium, riboflavin, Vitamin $A$, and Vitamin D because these are in short supply in vegetables. Susceptible to osteoporosis, all vegan women must carefully monitor their calcium intake since they consume no dairy products. Supplements from nonanimal sources, however, are readily available.

Based on these eight empirical factors, either Proposition 1.10 is literally false or it ambiguously equivocates the scope and meaning of the terms "vegetarian" and "adequate." To be true, the claim must be revised to one of the following propositions:

1.10a Except for pregnant women, infants, and small children, and only if vitamin and mineral supplements are included, a vegan diet is usually adequate for human nutrition.

1.10b An ovovegetarian diet is usually adequate for human nutrition but may require vitamin and mineral supplements.

1.10c A lactovegetarian diet is usually adequate for human nutrition but may require vitamin and mineral supplements.

1.10d An ovolactovegetarian diet is usually adequate for human nutrition but may require vitamin and mineral supplements.

Incorporating all of these necessary revisions (1.10ad) into one fully qualified (and hence true) proposition, Premise 1.10 now becomes:

1.10e Except for pregnant women, infants, and small children, and only if vitamin and mineral supplements are taken, a vegetarian diet (vegan, ovovegetarian, lactovegetarian, or ovolactovegetarian) is usually adequate for human nutrition. (Conjunction of 1.10a-d)

Moreover, in severe circumstances when the supplemented vegan or ovolactovegetarian diets are unavailable, such as in underdeveloped nations and during poverty or drought, even this revision would fail, and the meat diet would be circumstantially necessary.

To keep the argument sound, this revision of Premise 1.10 requires a revision of the conclusion. The following is a revision of the entire argument:

1.10e Except for pregnant women, infants, and small children, and only if vitamin and mineral supplements are taken, a vegetarian diet (vegan, ovovegetarian, lactovegetarian, or ovolactovegetarian) is usually adequate for human nutrition.

1.20 A meat (omnivorous) diet is adequate for human nutrition.

1.30a Therefore, except for pregnant women, infants, and small children, and only if vitamin and mineral supplements are taken, a meat (omnivorous) diet usually is unnecessary for human nutrition. (From $1.10 \mathrm{e}, 1.20)$

I think that these revisions significantly weaken and undermine the entire vegetarian agenda. Without a source for vitamin B-12 (usually eggs, milk products, or supplements), all vegetarians will become malnourished; and, without careful attention to iron in the diet or iron supplements, all age groups except adult males are at risk of becoming malnourished. All vegans are especially at risk in both regards. Vitamin B-12 deficiency and iron deficiency may take several years to appear and can be life-threatening; surely no one should run the risk. One's life quality can be markedly diminished for years, and recovery can be very slow. For most people, vegetarianism will not provide an adequate diet unless supplements are taken. Accordingly, the advice of many vegetarian authorities is to play it safe and take a supplement. From a moral perspective, I think that the vegetarian diet is so risky that no one should impose it on another person. 
Vegetarian parents face a particularly difficult dilemma: Should they compromise their moral beliefs by providing animal foods for their children, or should they risk malnutrition and underdeveloped children?

In addition to the empirical difficulties regarding Premise 1.10, the argument also involves significant conceptual confusion in the move from "adequate for human nutrition" in the premises $(1.10 \mathrm{e}, 1.20)$ to "unnecessary for human nutrition" in the conclusion (1.30a). To help you see my point, consider the following diets:

Kathy: Peanut butter, microwave biscuits, Big Macs, Diet Coke, candy bars, ice cream, and One-A-Day Plus Minerals vitamins.

George: Steak, potatoes, coffee, beer, and whiskey.

Dan: Meat and dairy products only due to rare, life-threatening allergy prohibiting all vegetable protein.

Alice: All four basic food groups as recommended by the U. S. Food and Drug Administration.

Bill Runningbear: Fish, seafood, caribou, and other meats from Arctic wildlife.

All of these diets are conceivably "adequate", especially if supplements are taken, as in Kathy's case. Supplements can make almost any diet "adequate." For Kathy, supplements are probably "necessary" to her "adequate" diet. Moreover, George can argue that whiskey is "necessary" to his diet since otherwise he might not get enough total calories. Kathy can similarly contend that Big Macs and candy bars are "necessary." Caloric deficiency is one form of malnutrition; adequate caloric intake is essential. In different senses, meat is "necessary" to both Bill's and Dan's diets: Bill's Arctic environment will not grow vegetables, and Dan's allergy prohibits vegetables. Also in different senses, Bill and Dan have "natural" diets: Bill's diet is restricted by his "natural" environment, and Dan's is limited due to a "natural" genetic deficiency. Probably Alice's diet is the only one that is "naturally" "balanced" and thereby "adequate," but her daily diet includes meat and would usually include items that are neither strictly "necessary" nor "natural," such as processed margarine and refined sugar. Her diet also occasionally includes "unnecessary" foods like chocolate chip cookies, fruitcake, and coconut pie, all of which collectively make up part of her "adequate" diet.

Perhaps by now my point is evident: the notions of "adequate," "necessary," "natural," and "balanced" are perhaps hopelessly ambiguous and imprecise. The confusion seems to be located in the singulardistributive and wholistic-collective aspects of the concepts. For example: as a distributive, singular component of a diet, whiskey may be "unnecessary" because it lacks most nutrients other than calories and can be replaced by more nutritious foods; but, as a component in a collective whole, the calories from the alcohol may be "necessary." Hence, the alcohol could be "distributively unnecessary" while being "collectively necessary." Moreover, except for highly refined foods like breakfast bars and astronaut cookies, no food taken singularly would be "adequate." As already noted, supplements can make virtually any diet "adequate," a fact that partly explains the current obsession with health foods and vitamins.

I do not think that it would be very helpful to continue to try to sort out these conceptual confusions, even if it were possible. Neither totally distinct nor completely free of equivocation, the relevant questions apparently are three: 1) What is a "normal" diet? 2) What is a "balanced" diet? 3 ) what foods are "naturally (routinely and regularly) available"? The complicated answers to these questions involve evolutionary, biosocial, physiological, nutritional, genetic, agricultural, ecological, socioeconomic, historico-temporal, and cultural aspects. For example, Scandinavians may be dependent upon seafood and dairy products if they are going to have balanced diets that can be produced naturally, regularly, ecologically, and economically in their harsh, cold climate. By way of contrast, due to the semidesert ecosystem and depending on population density, West Texans would probably have to depend upon range-fed animals such as cattle or sheep, especially during droughts and after the subterranean water sources currently used for irrigation are exhausted.

Deep ecologists predict that the best-and perhaps only-long-term agriculture for our environmentally crippled planet will be one where each local, ecologically autonomous bio-region produces "native" flora and fauna to feed its own population. Overpopulated regions will have to depopulate, and all people will eat primarily locally produced foods, which seldom occurs today except in underdeveloped 
nations. Porhaps the well-to-do of the future will eat like today's Japanese and the poor like today's Chinese.

Despite the empirical provisos and conceptual confusions, vegetarians may still contend that today most humans have a general duty not to eat meat because eggs and dairy products do not require killing the animals, supplements are readily available, and physicians can monitor one's health. Although prior generations may have been exempt and some underdeveloped nations may still be, modern pharmaceutical and medical rechnologies have now made vegetarianism healthy for virtually all people. Our culture has outgrown meat-eating.

Several reasons may make meat-eaters reject this general duty. First, worldwide ovolactovegetarianism $(1.10 \mathrm{~b}-d)$ would produce problems of unimaginable scope, especially if people were not permitted to eat the unproductive hens, cows, and calves. The animals would probably suffer horribly. Moreover, hens and cows would not do very well in many climates, either drastically draining the resources or requiring imported products.

Second, the vegan diet requires careful attention and supplements. Many people may find it to be too much trouble, too risky. Until our culture widely adopts and markets the diet, most people are probably too ignorant and uninformed to be adequately nourished. But this is surely only a transitional problem that can be remedied by education and marketing. In itself, having to pay close attention to nutrition in one's diet can also characterize meat-eaters, who can also be malnourished if their diets are not balanced. Mere inconvenience does not justify actions that are otherwise immoral.

Next, vegetarianism might work well for the middle classes but probably would put at risk the health of the laboring classes, who require more nutrients, purchase cheaper foods, are less educated, and are more habituated to the staple diet of their cultures-to the "meat and potatoes" or "pork and rice" diets. Many poor people, especially the rural poor, raise animals for food. They can raise a pig or have chickens with little more than garbage and table scraps. Admittedly many poor people, especially the urban poor, could purchase more food and be better fed if they did not buy so many expensive meat products, which they now mistakenly think they need in large quantities. Despite vegetarians' hopes of feeding the starving, impoverished masses with the grain now fed to livestock, vegetarianism is a middle-class movement. The nutritional, ecological, and agri-economic feasibility of widespread vegetarianism is questionable. So far, vegetarianism largely has been parasicic upon meat-eating cultures.

Finally, relying upon pharmaceutical companies for essential food-namely, vitamin and mineral supplements-may be technological madness. Is anyone morally required to depend upon pharmaceutical companies for health or nutritional peace of mind? Although readily available today in the developed nations, only a few generations ago these supplements were not widely available-and continue to be unavailable in many parts of the world. Perhaps someday on this planet people will consume plastic meals artificially synthesized on huge chemical farms, but such a time hopefully will never occur, at least not by choice. We are by nature omnivores. The farm and garden continue to capture most of our idyllic imaginations; we surround ourselves with pets, trees, shrubbery, and flowers. To give up nawural foods for supplements would be to lose part of our hereditary, biosocial, aesthetic, and perhaps mental health. The point is this: we may be forced by economic and ecological pressures to consume less and less natural animal products, but it is nutritionally unrealistic to expect our overpopulated planet to flourish on either vegan or ovolactovegetarian diets.

\section{The Empirical Argument from Pain}

Next in the extended argument, the term "pain" is added to the term "unnecessary" in the Empirical Argument from Pain. This sub-argument provides an empirical transition from the empirical nonnecessity of the meat diet to the moral Principle of Unnecessary Pain. Give the availability of a balanced vegetarian diet, meat-eating is in fact "unnecessary" for adequate nutrition (1.30, 1.30a). But even if meat-eating is in fact unnecessary for nutrition, vegetarianism does not follow unless pain also results. Meat-eating would be wrong according to the Principle of Unnecessary Pain only if the meat diet does in fact produce pain in the animals (1.50) and only if the meat diet causes more pain than the vegetarian diet (1.40). In other words, for the Principle of Unnecessary Pain to apply, there must be a conjunction of three empirically true propositions: (1) "A meat diet is unnecessary for human nutrition" (1.30), (2) "The vegetarian diet causes no pain in the animals" (1.40), and (3) "The meat diet causes pain in the animals" (1.50). These propositions need careful examination. 
As already established, meat-eating is in fact unnecessary for human nutrition only if the vegetarian diet includes eggs, milk products, or vitamin and mineral supplements $(1.10 \mathrm{a}-\mathrm{e}, 1.30 \mathrm{a})$. Worldwide ovolactovegetarianism, as argued earlier, is both impractical and exploitive of the animals. Although eggs and milk can be humanely and economically produced in some bio-regions as part of pluralistic crop ecology, worldwide dependence would result in ecological stress, increased agricultural monism, and immense pain for many of the animals, especially the old, unproductive ones. Surely slaughter would be more humane than abandoning the unproductive animals. Feeding the unproductive would consume valuable resources in a poorly diversified agricultural system overburdened by producing enough milk and eggs for the huge population of ovolactovegetarians. The problems we now have from abandoned pets make me doubt whether our society would provide humane care for unproductive cows and hens. The animal pain resulting from worldwide ovolactovegetarianism would surely be greater than that of a humane carnivorous world.

These considerations show that, if vegetarianism were adopted by a large population, most would have to be vegans. Therefore, when considered on a widespread scale, Proposition 1.40 is best regarded as false, except for veganism. It should be revised as follows:

1.40a A vegan diet causes no pain to the animals.

But as already noted, the protein content in the vegan diet is inadequate for many people, notably pregnant women, infants, and small children, and all vegans would need vitamin B-12 supplements. In a vegan world, B-12 might become a priceless commodity, although technological wizardry would hopefully come to the rescue. Perhaps eggs and milk would be produced for those requiring the extra protein, although technology might again meet the need. Nevertheless, animals probably would still be needed in some limited or severe situations, such as in impoverished regions and during droughts.

We now come to the claim that meat-eating causes pain, Proposition 1.50. This claim is conceptually ambiguous, having several possible and somewhat arbitrary meanings. I examine three of these.

First, it could mean that, even on the most conceivably humane and delightful animal farm, raising and slaughtering animals for meat would cause the animals at least some pain-perhaps minisculeeven though on balance they would live heavenly lives. Since meat is not needed for nutrition $(1.30,1.30 \mathrm{a})$, even this miniscule pain would be unnecessary. The obvious criticism of the interpretation is that the pleasure would vastly outweigh the pain-for the animals and humans. Unless animals have some status that prohibits exploiting and killing them, this first interpretation fails.

Second, Proposition 1.50 could mean that, if animals are raised and slaughtered for meat, the life of each animal in itself would have on balance more pain than pleasure to the individual animal. Although perhaps when human benefits are added the total balance might be positive, the animals themselves have miserable lives. They are mere means to our ends. When we do not need the meat $(1.30,1.30 \mathrm{a})$, it would be cruel to inflict such pain on the animals merely to satisfy our taste for flesh, as Rachels argues. In comparable cases where the lives of the animals on balance will be bad for the animals, such as stray dogs and severely diseased pets, we consider it our duty to euthanize the animals. Moreover, if we will not provide humane care to our pets, we regard it as our duty not to indulge in having them. Even if the moral aspect of this interpretation were unquestionably true, namely, if it were our duty to prevent animals from living lives that are on balance bad for the animals, the empirical aspect of this interpretation, namely, that the food animals live such lives, would still be questionable, especially when the animals are raised on traditional farms. Even by today's intensive methods, except for battery chickens, tethered sows, and veal calves, most food animals during their lives probably experience individually more net pleasure than pain.

Do we have a duty to prevent animals from living lives that are on balance bad for the animals? If this is a strict duty, then we must police wild nature, preventing predation except in optimal cases, feeding the hungry, caring for the diseased, rescuing the misfortunate, and so on. Such duties to the wild, if taken seriously, would quickly exhaust our economic resources and probably destroy our civilization. In contrast to wild nature, we surely do have such duties to our pets because we choose to have the pets and thereby enter into implicit contracts to provide for their needs in exchange for their being our pets. We do not have to have the pets. Not to care for them, or to kill them prematurely for our 
convenience, would be to break the contract, to betray the relationship we have with them.

One might object that the contract is not with the pets because they are not moral agents and so are not the kind of beings with whom we can make even implicit reciprocal contracts. All we break are our intentions, assuming we intended to keep the pets for a long time. If there is a contract at all, it is merely with ourselves. Although this objection makes important points, it still seems to me that poople are wicked when they plan to kill their pets premaurely for trivial reasons, such as not wanting to pay while on vacation for the pet's room and board, or desiring the animals only while they are frisky puppies or kittens.

But do such duties extend beyond pets to domestic food animals? Given the availability of an adequate vegetarian diet, we do not have to have the food animals. As with pets, we choose to have them. Therefore, surely we owe them at least humane treatment-that their lives be on balance good. But would killing them prematurely constimte betrayal? Unlike our pets, we have the food animals for the purpose of raising them for slaughter. Our intent throughout is to kill and eat them. They would not exist otherwise, and we have not even tacitly entered into a contract to provide for their needs beyond the optimal time of slaughter.

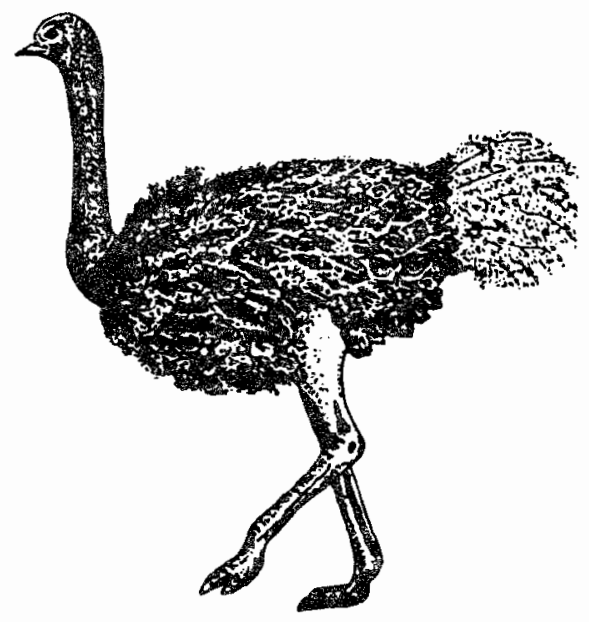

A not uncommon case, morally interesting but equally sad, is the food animal that is made inio a pet, often by children as 4-H or FFA educational projects. When these animals are slaughtered, conceivably both the child and the animal are betrayed and harmed.

Another duty to pets, and perhaps to other animals, is the duty to educate them. Probably not self-conscious in the wild, many animals may develop selfconsciousness, heightened rationality, and even a reciprocal sense of moral duty while loved and trained by their owners in the human sociocultural environment. ${ }^{11}$ Notable examples are seeing-eye dogs and chimpanzees. Ironically and inconsistently, it is precisely because animals have these capacities that they are desired as pets, and it is because they do not that they are exploited. As with uncivilized and uneducated human slaves, serfs, peasants, and laborers, we can leave the animals wild and untrained, thereby providing ad hoc grounds for exploiting and slaughtering the mindless brutes. We can also breed and socially condition both humans and animals to be inferior, tranquil, stupid, and aesthetically disgusting, thereby easing our elitist consciences.

Proposed by Holmes Rolston, III, the "homologous principle" asserts that, when we choose to domesticate animals, our minimal duty is to guarantee that they will live lives that are at least as good as, and as pain free as, their lives would have been in the wild. ${ }^{12}$ Moreover, their deaths by our hands must be at least as pain free as the deaths that they would have suffered in the wild. Rolston's principle correctly emphasizes that optional human actions ought to increase the net balance of good in the world, not decrease it. What I find unacceptable about the principle is that it permits doing intrinsically wrong actions in order to bring about optional goods, a point that I will develop more fully later.

Third and finally, Proposition 1.50 could mean that, when animals are raised and slaughtered for meat, the net calculus of combined pleasures and pains, including both animal and human pleasures and pains, is negative. This empirical claim is questionable, as argued below.

In order to imagine the multitude of factors involved, consider the following thought experiment. The question is a conflict of two worlds: $W_{1}$ is a vegetarian world, and $\mathrm{W}_{2}$ is a meat-eating, omnivorous world. If we assume that in both worlds human nutritional needs are met, then what is the relevant hedonistic difference between the two worlds? $W_{1}$ has the pleasure derived from vegetarian dishes without the pain to animals; 
whereas, $W_{2}$ has the pleasure derived from meat-eating plus whatever pleasure the animals experience during their lifetimes lessened by whatever pain the animals experience.

\section{$W_{1}$-Animals are not raised for food \\ No relevant animal pain. \\ No relevant animal pleasure. \\ Human pleasure from vegetable dishes.}

\section{$W_{2}$-Animals are raised for food:}

Animal pleasures while alive.

Animal pains while alive.

Animal pains during slaughtering.

Human pleasure from vegetable dishes.

Human pleasure from meat dishes.

In what sense can we say that one world is better or worse than the other? In $W_{2}$, if the animals are raised humanely and slaughtered mercifully, their lives on balance would yield more pleasure than pain. To this pleasure would then have to be added the pleasure of the meat dishes. Therefore, $W_{2}$ would have on balance more pleasure than $\mathrm{W}_{1}$ - except when the food animals are mistreated.

In estimating the utility calculus, the pleasures of the food animals themselves must be taken into account. If the animals raised in W2 were also raised but not slaughtered, then billions of the vegetarian world would surely have more pleasure. But, if no one ate meat, then billions of animals would not exist and would not experience any pleasure. Most food animals could not survive in the wild, and society surely would not pay for their food and veterinary costs. An oversight of some vegetarians is to desire the healthy animal populations of $\mathrm{W}_{2}$ without the pain of killing. Admittedly, the continued pleasurable existence of any particular animal in $\mathrm{W}_{2}$ would make $\mathrm{W}_{2}$ a better world, but $W_{2}$ would not exist and that animal would not exist if $\mathrm{W}_{2}$ were not camivorous. The utility contrast should be between $W_{1}$ and $W_{2}$, not between different possible states of $W_{2}$. In addition, in $W_{2}$ when the particular animal is killed and eaten, it is usually replaced by another animal that experiences pleasure until it, too, is killed and replaced. This is the so-called "replaceability argument." 13 In other words, by virtue of the fact that it is a carnivorous world, $\mathrm{W}_{2}$ sustains a level of pleasure (reduced by the animals' pain) that on balance is probably higher than the vegetarian world.
The animals would not exist and would not enjoy any life if they were not to be eaten.

Some vegetarians urge that $W_{1}$ would produce millions of happy animals in the wild on lands now used for pasture and animal feed. Nature is not "red in tooth and claw" because most species are herbivores, not carnivores. Less cultivation would free vast acreages for reforestation, wilderness, and wildlife. Despite these idyllic wishes, even if we could return the land to its aboriginal innocence, animal populations and pleasures would probably not be maximized thereby. Animals in the wild often suffer-from disease, malnutrition, stress and predation. Moreover, many wild species flourish in greater numbers and health in a mixed rural-wildemess. Rolston states:

\section{The climax forest of an ecosystemic succession is usually not suited for the maximum number and kinds of fauna and flora, and this succession can be interrupted by agriculture with benefit to those natural species that prefer fields and edging. There are more deer in Virginia now than when the Indians inhabited its visually unbroken forests, and that is probably true of cottontails, bobwhites, and meadowlarks. Suitable habitat for all but a few of the wildest creatures can be made consistent with the rural use of land. ${ }^{14}$}

Consequently, the best hedonistic world is some version of $\mathrm{W}_{2}$, one with both wild and domestic animals suitably balanced by the agricultural and ecological sciences.

Moreover, it seems that a pleasure-pain calculus taken by itself would require that we eat meat. Because $W_{2}$ results on balance in more pleasure than $W_{1}$, we are obligated by utility considerations to eat meat. Unless animals have some status (or intrinsic value) that would prohibit their slaughter for food, we are not only free to eat meat but are obligated to do so. Of course, we should not raise animals to such an extent that feeding the animals would produce a world ecological crisis or food shortage, and we would not eat meat to such an extent as to produce our own illhealth. But a certain optimum amount of meat-eating would seem to be obligatory because it would raise the net level of both human and animal pleasure without significant losses due to animal pain. Numerous food animals can be raised on garbage and rangelands unsuitable for cultivation. 
Although I would not defend the following argument, it seems plausible to me to argue on hedonistic utilitarian grounds that another world $\left(W_{3}\right)$ populated only by nonhuman animals would be a better hedonistic world than either $W_{1}$ or $W_{2}$. Without human beings converting natural habitats into cities and farmlands, sentient animais would be free to reproduce and experience large amounts of pleasure, reduced of course by the pains of predation, disease, and nawral disaster. Or, pernaps the best world would be a world with huge nonhuman animal populations and only a few human shepherds and veterinarians to care for the animals. If this argument is even plausible, then hedonistic utilitarians need to take seriously a duty to bring about the extinction of the human species, unless human beings have intrinsic value and capacities for nonhedonistic intrinsic goods that make them superior to nonhuman animais. If human beings are genuinely superior, then the better world would seem to be some version of $W_{2}$ where human beings would seek to maximize the populations of both their own species and other species to the extent warranted by ecological factors and genuinely qualitative living for all. The mere plausibility of $W_{3}$ is a reductio ad absurdum for the hedonistic utilitarian argument.

Vegetarians may still insist that there is a sense in which $W_{2}$ is not a better world than $W_{1}: W_{2}$ involves killing and eating animal flesh. If this statement is a moral judgment (rather than, for example, an aesthetic one), it assumes that animais have some kind of moral status beyond mere pleasure-pain sentience that makes killing them wrong. Consider another world $\left(W_{4}\right)$ where unwanted day-old human babies are painlessly killed and eaten. ${ }^{15}$ Will a similar "pain" argument apply? Surely some humans would derive pleasure from eating roasted baby, and $\mathrm{W}_{4}$ would then seem to be a better world than $W_{2}$ or $W_{1}$. But most of us would object that the act of killing and eating humans for food makes $W_{4}$ a worse world, but our objection would not be a hedonistic one because it assumes that human beings have an intrinsic value that prohibits killing and eating them for food. The reason we do not kill and eat human beings--regardless of the pleasure produced - is because they have a superior status above that of other animals. Unless it can be established that food animals have a human-like status, or at least a status sufficiently high enough to prohibit killing and eating them, meat-eaters are free to continue their diets. Because most food animals are social, probably conscious, and to some extent rational, many vegetarians hold that the animals have a status far above that of mere sentience.

Finally, vegetarians may contend that $\mathrm{W}_{2}$ can never be humane: the huge world population and demand for meat will necessitate intensive animal husbandry and monstrous slaughterhouses. Meat-eaters are selfdeceived. The fact of the matter is, the meats in the local supermarkets are the bodies of animals that lived homible lives and died cruel deaths. In our capitalistic economy, one cannot eat meat, even moderately, without contributing to the market demand for meat and encouraging the abusive system. It is unrealistic to envision $\mathrm{W}_{2}$ as a humane worid of family farms and small butcher shops. In our densely urban world, city dwellers cannot reasonably be expected to buy directly from small farmers and local butchers. The meat-grain industry is big business controlled by a monopoly of a few multinational corporations. In the United States, one-third of all raw materials per year goes to livestock foods, which is more than the entire oil, gas, and coal industries combined. ${ }^{16}$ Allegedly, reform is impossible, and therefore the only moral alternative is abstinence from all flesh foods.

In rebuttal, meat-eaters have argued that abstinence is not required as long as one's meat consumption is moderate and as long as one actually works for reform. ${ }^{17}$ I have lived on a family farm, and I know that the animals can be humanely raised and mercifully slaughtered. Like poverty, overpopulation, nuclear armament, and the environment, justice in food production and distribution is an enormous problem, but the enormity of the problem and the economic and political power of agribusiness does not entail inaction, especially in a democracy. Conscientious meat-eaters can join in the movement to help the family farmers. Through tax breaks and legislation, they can help insure that lands near cities will be reserved for small farms that will be used for food production for the neighboring cities. Small farms raising livestock, vegetables, eggs, poultry, and dairy products can thrive in these locations. Farmers' markets and excursions into the country to buy food would bring consumers directly into contact with producers. Meat-eaters can work to stop overpopulation and to pass laws regulating agribusiness. Many city-dwellers can become weekend farmers. Gardening can be taught. We can insist that grocers supply range-fed beef and barnyard eggs and poultry. Moderation with reform is not impossible. 
In conclusion, the Empirical Argument from Pain fails, except for the vegan diet, which has morally significant nutritional limitations. Moreover, humane animal husbandry would increase the balance of pleasure, not decrease it. Although contemporary intensive farming methods are deplorable, genuine efforts for moderation and reform are morally responsible ways to address the problem. Consumers of meat are no more responsible for the abuses of agribusiness than consumers of heating oils are responsible for the abuses of oil producers. Unless other moral considerations intervene, and perhaps they do, omnivores would seem to be free to raise food animals humanely and to kill them mencifully. Such prohibitions might be grounded in the essential status or dignity of the animals as living, conscious, sentient, rational beings living in a community. ${ }^{18}$ If it is wrong on such grounds to exploit and kill animals, then no amount of humane treatment and good consequences would justify the abuses.

\section{The Moral Argument from Unnecessary Pain}

Finally, the third step in the extended argument needs attention. Whereas the other two steps were empirical, this step is moral (or evaluative). The moral maxim prohibiting unnecessary pain is applied to meat-eating. For instance, in an emotive passage, Stephen R. L. Clark states:

...whatever else be true, whether there be gods or only atoms, whether men are significantly superior to non-human animals or no, whether there be a life to come or this poor accident be all, this at least cannot be true, that it is proper to be the cause of avoidable ill. There may be other moral principles than this, but this at least is dogma. And if this minimal principle be accepted, there is no other honest course than the immediate rejection of all flesh-foods and most bio-medical research. ${ }^{19}$

The Principle of Unnecessary Pain (also called the Principle of Noninjury) is a deontological (that is, nonteleological or unconditional) moral principle that has prima facie priority over all other moral principles, including the Principle of Beneficence (which is succinctly put, "do good"). ${ }^{20}$ In other words, pain can be inflicted (or injury done) only in cases of genuine conflict and only in order to prevent an unavoidable worse evil. Although we also have a duty to do good according to the Principle of Beneficence, we are prohibited from doing evil as a means to bring about good. The Principle of Utility, that the good should be maximized, is secondary to and derivative from the Principles of Noninjury and Beneficence. Utilitarian, teleologically based actions could conceivably justify blatant wrongs, such as secretly killing innocent persons in order to bring about good; and, the priority of the Principle of Noninjury prohibits such acts.

How do these principles apply to meat eating? Hedonistic utilitarianism would justify meat-eating, as explained above, as long as the animals live on balance good lives. They benefit and meateaters benefit. In the evaluative, moral step of their argument, hedonistic utilitarians appeal to the Principle of Beneficence and the Principle of Utility. But, unless it can be shown that death is not a harm to the animals or that the conflicts are legitimate and unavoidable, this utilitarian move would be undercut by the prima facie priority of the Principle of Noninjury. When the meat is not needed for nutrition, the pain and death of the animals are avoidable, illegitimate wrongs, and these acts would not be justified by appeal to some higher, optional good, including human or animal welfare. Meat-eating would be prohibited except in particular cases of legitimate conflict wherein a worse evil would result without the meat. When the purpose is merely to achieve some greater utilitarian good, such as dietary convenience, gustatory delight, or agricultural efficiency, meat-eating would not be justified. Only those meat-eaters actually and unavoidably needing the meat for nutrition would be justified. Moreover, despite its overwhelming positive net utility, not even the delightfully good omnivorous world considered earlier-where the animals live on heavenly farms and experience only miniscule pain - would be justified because evil is being done to bring about good.

The Principle of Noninjury would not prohibit animal husbandry, but it would probably make the practice unprofitable. Animals could be farmed as long as they were given good lives and were allowed to live out their natural lives, dying of old age. Eggs, milk, and wool could be obtained, and the bodies of the deceased, aged animals could be used for food and clothing. ${ }^{21}$

In an insightful version of the Principle of Utility, Rolston attempts to justify meat-eating by appeal to 
what he calls the "Principle of Value Capture."22 According to this notion, the values of a lower level are "captured" and carried forward, or transcended, in a higher level or gestalt. Animal farming and meateating help make possible the qualitatively higher values of cuiture, values such as civilization, society, religion, the fime arts, and intellectual reflection. Rolston's insight, I think, is the recognition that values are qualitatively different and that pain is often endured in order to bring about qualitatively superior goods. Nevertheless, if if were correct, Rolston's principle would seem to justify discriminatory practices such as slavery. According to the Principle of Non-Injury, we are not justified in inflicsing such pain on innocent beings merely to bring about a positive good.

At least two other moves are open to traditional meat-eaters and animal farmers. First, as mentioned earlier, they can argue that food animals are not the kind of beings to whom morality applies-including the Principle of Unnecessary Pain. Beings lacking in full rationality, language, self-consciousness, and continuity of self-identity across time-that is, merely sentient beings-are devoid of any "self" that can be harmed or injured. "Pain" in such self-less beings is not really pain but simply neurophysiological activity. Their mental states, if such exist at this low level of psychic activity, are little more than isolated packages of biochemical, neuronal activities. If killed quickly, such beings would not be harmed, at least not in any morally relevant sense.

This response is, I think, conceptually and morally correct but, its application to most food animals is empirically mistaken. Except perhaps for fish, food animals are not merely sentient automatons. Evolutionary and physiological evidence indicates that animal species comprise a neurophysiological continuum such that radical separation of homo sapiens, despite our superiority, is mistaken. Similar brains, central nervous systems, sensory organs, and behaviors convince me that the above response is too reductionistic. Cattle, sheep, hogs, and perhaps chickens are highly sentient and conscious social beings who live in communities, have memories, communicate with each other, recognize each other, and solve genuinely novel problems. ${ }^{23}$ Killing such creatures, even painlessly, does them irreparable harm. Therefore, the Principle of Unnecessary Pain applies.

The second move is to argue that the Principle of Noninjury is merely prima facie. At issue are the kinds of conflicts that legitimately override the principle. Nutrition and health are surely significant and legitimate overriding moral conflicts; no autonomous person can reasonably be coerced to put their health at risk. Also legitimate and unavoidable are the following: humans are by nature omnivores; widespread humane ovolactovegetarianism is impractical; small-scale humane ovolactovegetarianism is parasitic on meatbased agriculture; veganism is impossible for many people; veganism requires supplements; and all forms of vegetarianism are nutritionally risky. Although not idealistically unavoidable, several contemporary sociocultural factors are also relevant: beliefs about animals are often religiously based and dogmatically implacable; agribusiness is the most powerful and weaithy multinational industry $y^{24}$ and is unlikely to stop meat production; despite higher regard for animals and widespread criticisms of behaviorism, most animal ethologists and psychologists still deny the selfconsciousness of food animals; underdeveloped and impoverished countries need to utilize every conceivable food source, including animals; widespread vegetarianism might disproportionately risk the health of the laboring classes, especially the rural poor; in a strained, overpopulated world ecosystem, numerous food animals could be raised on garbage, noncultivatable pastures, and other foodstuffs inedible to humans; and, many philosophical ethicists for good theoretical and practical reasons consider meat-eating morally permissible, if not morally justified. Unless food animals are the kind of beings, like humans, that cannot be used as mere means to ends, then surely these factors collectively override the prima facie prohibition against inflicting unnecessary pain. As a matter of fact, the pain inflicted is not unnecessary.

\section{Conclusion}

Individually and collectively, ail three steps in the vegetarian argument from unnecessary pain fail: the Empirical Argument from Nutrition because equivocation occurs regarding what is meant by "vegetarian," "adequate for human nutrition," and "unnecessary for nutrition"; the Empirical Argument from Pain because food animals can be raised humanely and killed mercifully, and because moderation in consumption and actual efforts for reform are morally acceptable responses to the current abuses; and, the Moral Argument from Unnecessary Pain because the prima 
facie obligation not to inflict pain is overridden by the nutritional risk of vegetarianism (especially veganism) and by numerous contemporary sociocultural circumstances beyond the individual's control. Collectively, the arguments succeed only for those individuals who know they can do well on a vegan diet. Based on the Principle of Unnecessary Pain, perhaps all persons would then have at least a prima facie duty to try to be vegans and thereby to discover whether they would do well on the diet. Nevertheless, because the Principle of Unnecessary Pain is merely prima facie and because the risks and sociocultural conflicts are genuine, I do not think anyone has a duty even to try to be a vegan.

Briefly discussed a few times in the above analysis, another argument would trump these considerations. If food animals are self-conscious and rationally autonomous, then they would possess the same moral status that prohibits exploiting and killing humans. Although most food animals are probably not selfconscious, a few particular individuals perhaps are. ${ }^{25}$ The issue then becomes whether the status of those unusually and atypical few confers indefensible moral status on the entire species. In some cases I think it does. For instance, the fact that some chimpanzees are self-conscious entails that murdering any chimpanzee is criminal. Fortunately, some entire species of food animals, such as shrimp and fish, are unquestionably not self-conscious.

Because meat-eating is so deeply entrenched in our culture, moderation and reform are probably bestboth for the health of individual humans and for the long-term benefit of the exploited food animals. Meat does not need to be eaten daily; a few servings weekly are more than sufficient to off-set any risk in a largely vegetarian diet. As a means of reform and in comparison to abstinence, moderation stands a far better chance of being widely adopted in our implacably carnivorous society and thereby of improving the lives of food animals.

The collective failure of these arguments seems to me to be significantly more tragic than their individual failures. I wish things were otherwise. I wish that we were not as nutritionally dependent upon meat as we are and that the sociocultural circumstances were better. But, we are naturally omnivores, we are grossly overpopulated, and we are greedily capitalistic. Although it should not be imposed on autonomous persons, being a vegetarian is good because it reduces the demand on our environment, strikes a blow against capitalistic injustices, and spares at least a few animals pain and death. And perhaps a few of those so spared are self-conscious.

\section{Notes}

${ }^{1}$ Several individuals have criticized earlier drafts and parts of this paper. Many of the ideas originated in conversations with my colleague, Joseph D. Stamey of McMurry College, who responded to early versions at the Association for the Scientific Swdy of Religion: Southwest (March 1987) and the North Texas Philosophical Association (October 1988). Especially helpful were comments by Thomas Wheaton Bestor of the University of Washington at the Pacific Division of the American Philosophical Association (April 1988). Discussions also occurred at the New Mexico and West Texas Philosophical Association (April 1987) and the XVIII World Congress of Philosophy (August 1988).

${ }^{2}$ For a longer analysis, see my "Vegetarianism and the Argument from Unnecessary Pain," Southwest Philosophical Studies 10 (Spring 1988): 92-100.

${ }^{3}$ The Empirical Argument from Nutrition can also be stated in a Modus Ponens version:

2.10 If a vegetarian diet is adequate for human nutrition (1.10), then a meat (omnivorous) diet is unnecessary for human nutrition (1.30).

1.10 A vegetarian diet is adequate for human nutrition.

1.30 Therefore, a meat (omnivorous) diet is unnecessary for human nutrition. (From 2.10,1.10)

Except for the move from "adequate for human nutrition" to "unnecessary for human nutrition," the Modus Ponens version would appear to be no more than a conditional tautologous truism, as seen in the following analysis:

$2.10 \mathrm{a}$ If a vegetarian diet is adequate for human nutrition (1.10), then a non-vegetarian diet (namely, a meat, or omnivorous, diet) is unnecessary for human nutrition (1.30). (From 2.10)

$2.10 \mathrm{~b}$ If vegetarianism, then not non-vegetarianism. (From 2.10a)

$2.10 \mathrm{c}$ Symbolically: $p \rightarrow--p$. (From $2.10 \mathrm{~b}$ ) Tautologies are necessarily true and therefore empty of inferential content. In other words, the argument would be a pseudo-argument that upon analysis reduces to the empirical assertion that vegetarianism can be adequately nourishing. If this analysis were correct, the conclusion (1.3) would be merely a reassertion of the vegetarian premise (1.10). What makes me reject this analysis is that the shift from "adequate" for nutrition in the premises $(1.10,1.20)$ to "unnecessary" for nutrition in the conclusion (1.30) is omitted in the move from $2.10 \mathrm{a}$ to $2.10 \mathrm{~b}$. Despite its deficiency, this suggestion does 
call our attention to a problematic aspect of the argument: the shift from "adequate" to "unnecessary" nutrition.

${ }^{4}$ James Rachels, "Vegetarianism and "The Other Weight Problem'," in World Hunger and Moral Obligation, ed. William Aiken and Hugh La Follette (Englewood Cliffs: Prentice-Hall, 1977), p. 185.

${ }^{5}$ Mary Midgley, Animals and Why They Matter (Athens: University of Georgia Press, 1983), p. 27.

${ }^{6}$ Jane Brody, Jane Brody's Nutrition Book (New York: Bantom Books, 1981), pp. 434, 442-43.

${ }^{7} \mathrm{Ibid}$, p. 443.

${ }^{8}$ Ann C. Grandjean, "The Vegetarian Athlete," The Physician and Sportsmedicine 15 (May 1987): 191.

${ }^{9}$ Barbara F. Harland and Michael Peterson, "Nutritional Status of Lacto-Ovo Vegetarian Trappist Monks," in Nurition and Vegetarianism: Proceedings of Public Health Nurition Update 1981, Chapel Hill, ed. John J. B. Anderson (Chapel Hill, NC: University of North Carolina Health Sciences Consortium, 1982), p. 75.

${ }^{10}$ These empirical facts were gleaned primarily from four popuiar, nutritionally reputable sources: Laurel Robertson, Carol Flinders, and Bronwen Godfrey, Laurel's Kitchen: $A$ Handbookjor Vegetarian Cookery and Nutrition (New York: Bantom Books, 1976); Laurel Robertson, Carol Flinders, and Brian Ruppenthal, The New Laurel's Kitchen (Berkeley: Ten Speed Press, 1986); Frances Moore Lappé, Diet for a Small Planet, rev. ed. (New York: Ballantine Books, 1982); and Jane Brody, Jane Brody's Nutrition Book. Empirical research by nutritional scientists using the latest methods of anthropometric, demographic, and biochemical analyses overwhelmingly confirm my list of "facts." See especially the following collection of papers and research reports presented in 1981 at a national nutrition conference: John $J$. B. Anderson, ed., Nutrition and Vegetarianism: Proceedings of Public Health Nutrition Update 1981, Chapel Hill (Chapel Hill, NC: University of North Carolina Health Sciences Consortium, 1982)

11 See Richard A. Watson, "Self-Consciousness and the Rights of Nonhuman Animals and Nature," Environmental Ethics 1 (Summer 1979): 99-129.

${ }^{12}$ Holmes Rolstorn, III, Envinommental Ethics (Philadelphia: Temple University Press, 1988), pp. 61, 79.

${ }^{13}$ R. G. Frey, Rights, Killing, and Suffering (Oxford: Basil Blackwell, 1983) pp. 159-73.
${ }^{14}$ Holmes Rolston, III, Philosophy Gone Wild (Buffalo, NY: Brometheus Books, 1986), p. 42.

${ }^{15}$ To eliminate both Irish overpopulation and starvation, Jonathan Swift's sarcastic "modest proposal" was that their babies be roasted and eaten.

${ }^{16}$ Lappé, Diet for a Small Planet, p. 66.

${ }^{17}$ Frederick Ferré, "Moderation, Meat, and Morals," Inquiry 29 (December 1986): 391-406.

${ }^{18}$ This approach is used by Tom Regan in The Case for Animal Rights (Berkeley: University of California Press, 1983).

${ }^{19}$ Stephen R. L. Clark, The Moral Status of Animals (New York: Oxford University Press, 1984), p. xiii.

${ }^{20}$ See William K. Frankena, Ethics, 2d ed. (Englewood Cliffs, NJ: Prentice-Hall, 1973), p. 47.

${ }^{21}$ Regarding the nonexploitive usage of animals, see S.F. Sapontzis, Morals, Reason, and Animals (Philadelphia: Temple University Press, 1987), pp. 201-6.

${ }^{22}$ Rolston, Environmental Ethics, pp. 79, 83.

${ }^{23}$ See Donald R. Griffin, Animal Thinking (Cambridge: Harvard University Press, 1984), and Mary Midgley, Animals and Why They Matter (Athens, GA: University of Georgia Press, 1983).

24 See Lappé, Diet for a Small Planet, pp. 43-49, 66.

${ }^{25}$ Demonstrating self-consciousness in nonlinguistic animals is exceedingly problematic, both empirically and conceptually, as argued by Jonathan Bennett in his Presidential Address to the American Philosophical Association ("Thoughtful Brutes," Proceedings of the American Philosophical Association 62 [September 1988]: 197-210). See also Watson, "Self-Consciousness," pp. 99-129.

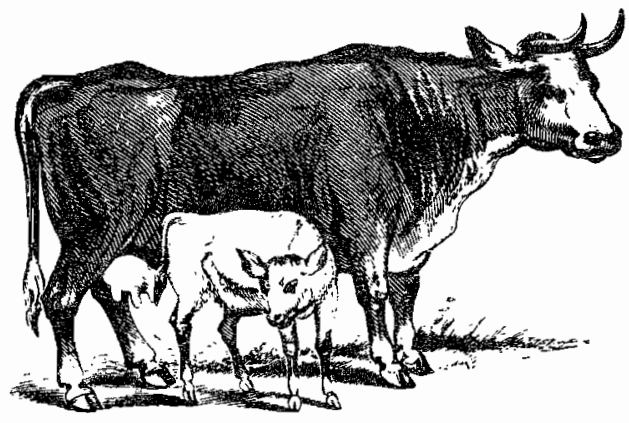

